\title{
David McCollum
}

\section{Scotland and Brexit: identity, belonging and citizenship in uncertain times}

\begin{abstract}
This article offers some reflections on the lessons readers might take from the papers in this special issue. These are framed through consideration of three key themes: Scottishness, nationhood and national identity; the search for belonging, not least in relation to migrants' emotional responses to Brexit; and the practical questions that Brexit poses for citizenship(s) and 'settled' status. In considering these themes, attention is drawn towards three areas which are ripe for further study. Several of the articles bring into focus the notion of Scottish exceptionalism, provoking questions about what impacts this exceptionalism, or perhaps more importantly perceptions of it, may have at policy and attitudinal levels. Questions too, are posed about the heterogeneity of perception, experience and response to Brexit amongst ECE migrants in Scotland. Finally, it can be seen that Brexit has been a protracted process and a source of anxiety and anguish, not least for those who have made Scotland their home. Looking forward, there will be more Brexit related tension to come, a prospect hugely complicated by the impacts of Covid-19.
\end{abstract}

Keywords: Scotland, Brexit, Identity, Belonging, Citizenship

David McCollum is Senior Lecturer in the School of Geography \& Sustainable Development, University of St Andrews 


\section{Introduction}

It is a pleasure to offer a commentary on the articles that constitute this special issue and which add much needed insight into the themes of citizenship and belonging in post-Brexit Scotland. Brexit is undoubtably a defining issue of our time, and its repercussions will be potentially be multifaceted and enduring; not least for those whose sense of identity, belonging and citizenship it most calls into question. The efforts of the social science community in responding to these aspects of this ongoing geopolitical shock have been commendable (see for example Botterill et al, 2018; Duda-Mikulin, 2019; Lulle et al, 2018). This timely intervention builds on a nascent evidence base which is beginning to shed light on questions of identity and the dynamics of migrant experiences, expectations and preferences in Scotland in the context of the Brexit referendum result, the drawn-out political ramifications which have followed it and the eventual official departure of the UK from the European Union on $31^{\text {st }}$ January 2020 (Gawlewicz and Sotkasiira, 2020; Botterill 2018; Mulvey and Burnett, 2019).

At the time of writing (May 2020) Scotland and the wider UK finds itself in a period of great uncertainty. Whilst Britain is officially no longer a member of the EU, the eventual passing of the European Union Withdrawal Act by the UK Parliament in early 2020 means that during the so-called transition period, EU law will continue to apply in and in relation to the UK until the 31st December 2020. After this period the UK Government has proposed the application of a Points Based System to replace the Freedom of Movement that currently applies to migration between the UK and EU. In some respects then, the current transitional phase is thus one of Brexit in name only, with much of the difficult and potentially fractious negotiations and political settlements still to come. The Scottish Government meanwhile has persistently argued that a 'one-size fits all' UK-wide immigration policy is ill suited to the particular demographic needs of Scotland. In the days prior to Britain's exit from the EU, the Scottish Government launched its proposals for a tailored migration policy for Scotland (2020), whilst simultaneously making the case for another referendum on Scottish Independence. Shortly afterwards however, debates surrounding constitutional arrangements between Edinburgh, London and Brussels were thrown into a state of stasis due to the unprecedented turmoil thrown up by the global covid-19 pandemic. As such, there is much anxiety amongst the general populace concerning physical and mental wellbeing and household and national finances in the context of a monumental health crisis and ongoing constitutional upheaval around Brexit and Scottish independence. These uncertainties are particularly acute amongst migrant and ethnic 
minority populations, who are most at risk of physical, mental and financial distress due to the pandemic (Loopstra, 2020) and whose sense of belonging, in a psychological and legislative sense, is being jeopardised by Brexit.

The articles in this special issue offer valuable insights into the challenges faced by these groups in Scotland. The papers aptly stress that immigrant and ethnic minority groups already faced considerable difficulties regarding citizenship and belonging and highlight how these have in many cases been exacerbated by the toxic combination of;

- The protracted Brexit process: the bitterness of the debate in the lead up to the plebiscite (in which the Leave side successfully weaponised the issue of immigration)

- The shock of the referendum result (including the stark contrast between the outcomes at the Scotland and UK scales)

- The three-and-a-half-year period of political chaos between the vote and the actual departure from the EU

- The considerable ongoing uncertainty about what will happen after the transition period ends (December 2020 at the time of writing).

Below I offer some reflections on the lessons that can be gleamed from the papers in this special issue in relation to three key themes. The commentary concludes with consideration of how these contributions can inform how research in this area might fruitfully proceed in these times of protracted constitutional uncertainty.

\section{Scottishness, nationhood and national Identity}

Two articles in particular grappled with the complexities of nationhood and national identity, specifically in the context of Brexit and Scottishness. Anna Gawlewicz's contribution is laudable for its engagement with the prevalent notion than Scotland is 'different' in terms of migration than its bigger and allegedly more hostile southern neighbour, England. As noted by the author, narratives of distinctiveness are a familiar facet of nationhood, and Scotland is no different in this respect. However, these discourses have taken on added potency against the backdrop of the 2014 independence referendum and in the 2016 Brexit vote and its aftermath. Mainly nurtured by political and media elites, often with a somewhat self-congratulatory tone, 
the thesis of a distinctive Scotland with regards to questions of migration has only rarely been considered from the perspective of 'normal' people (Meer, 2015; Leith and Soule, 2011) and this is where Gawlewicz's analysis has particular utility. Reassuringly for the successive First Ministers who have been active in framing these narratives of difference, and the wider segment of wider civil society that endorses them, Gawlewicz's investigations in the East End of Glasgow do indeed suggest that projections of Scotland's distinctiveness have been internalised by the wider populace. This chimes with existing research which finds that migrants often feel less hostility north of the border (Sigona and Godin, 2019). It also matches the absence of the spike in Brexit related racially motivated hate crime that was recorded in England and Wales following the vote (Hepburn, 2020). However, it is worth noting that it would be a mistake to perceive or represent Scotland as being immune to the anti-immigrant sentiment that is so well documented in England. Indeed, analysis of survey data by Curtice and Montagu (2018) finds little difference in attitudes towards immigration on the part of the general population in Scotland compared with England and Wales. Likewise, the literature contains plenty of examples of the prejudice faced by ethnic minorities in Scotland (Bonino, 2019; Mostafa, 2018). As noted by Davidson et al (2018) recently, this mixed bag of evidence thus suggests that the top down romanticised narrative Scottish distinctiveness may not in fact reflect the values of a significant section of Scotland's population. As Gawlewicz acknowledges, her analysis engaged with residents of the East End of Glasgow who were relatively pro EU. It is worth keeping in mind that a significant minority of voters in Scotland (nearly 2 in 5) backed Brexit and that many Remain voters may have also held unfavourable views towards immigration. Future research in this area could thus fruitfully aim to uncover the motives behind the positioning of Scotland as more welcoming of migrants, whether these narratives actually reflect the values of the general public and the extent to which existing and potential migrants are attuned and responsive to these framings. Such questions are not inconsequential. For example, calls for enhanced Scottish autonomy over immigration policy are premised on the basis of Scotland's distinctive migration experiences and preferences. Research in this area should also been sensitive to the possibility that religious sectarianism and Anglophobia may be acting to displace some overtly anti-immigrant sentiment in Scotland (McCollum et al, 2014).

Consideration of the somewhat neglected issue of the prejudice experienced by some English residents of Scotland takes us to another significant 'migrant' group that is often overlooked in 
discussions over belonging in the context of Brexit: Scottish people living in England. As Leith and Sim note, Scots are one of the largest socio-political sub-groups within England. They are in the peculiar position of living outwith their country of birth yet within the same nation-state. The political preferences of this sizeable diaspora regarding Scottish independence and Brexit remains unclear, however Leith and Sim's paper is to be congratulated for informing us of how some members of this cohort are interpreting and responding to these contemporary constitutional upheavals. Whilst their research occurred prior to Brexit, their contention that it provides useful insights into the thinking of the diaspora in regard to Scotland, Scottish constitutional matters and the wider relationship with the UK is a valid one. The main empirical part of the paper inevitably reveals a diversity of opinion amongst Scottish inhabitants of England. Greater clarity regarding how their residence of England in particular shaped their views on Scottish constitutional matters might have been welcome. How would the findings have differed had the research been conducted in Moray and Strathclyde instead of Merseyside and Shropshire for example? The authors somewhat undersell their analysis by stating that 'the numbers who moved south has not been great'. Whilst this is patently the case from the perspective of England's considerably larger population, the 708,872 Scots born residents of England is a significant fraction of the 4,411,884 Scots-born residents of Scotland (at the time of the last Census in 2011, Leith and Sim, 2019). The final main section of the paper offers the most insight into the position of Scots in England within the current situation of constitutional uncertainty. Whilst rather speculative, the concerns about travel between England and Scotland, citizenship, the decision about whether to return and hostility should Scotland become independent lay the groundwork for future research to consider questions of how the Scottish and European questions are unsettling understandings of identity, belonging and citizenship amongst the many hundreds of thousands of Scottish residents of England and vice versa. Key questions here could include;

- Is there growing hostility to Scottish residents in England and English residents of Scotland and to what extent are they related to the Brexit and Scottish independence debates?

- Might the current constitutional turmoil lead to some Scots deciding to move back to Scotland (and a similar reverse flow of English residents of Scotland moving south) post-Brexit?

- Are fewer Scots moving south and English moving north because of this uncertainty? 
- How do feelings of identity, belonging and citizenship interact with other significant determinants of the migration decision making process amongst Scots in England?

\section{Hierarchies and boundaries of belonging: migrants' responses to Brexit}

Another key theme explored in the special issue was how Brexit might be unsettling migrant feelings of belonging in Scotland. Three papers in particular illuminated the feelings of attachment to place of East-Central Europeans (ECE), including Roma, and reflected on how these may evolve going forward in an era of socio-political and geographical change.

Rebecca Kay's article on in/security and migration in the context of geopolitical transformations is a significant and timely reminder that, whilst Brexit is the most significant geopolitical shock that many of us have experienced, for many ECE migrants it is merely yet another geopolitical transformation that simultaneously evokes material and emotional insecurity. Kay and many of the other authors in the special issue echo the point that Brexit, contrary to popular belief, is not simply a significant event in time. Rather it needs to be conceived of as a protracted process over time. In the case of many of the impressive quantity of East-Central Europeans involved in her research, the insecurities of Brexit are part of a much longer continuum of past inequalities that have necessitated life rebuilding projects and the spatial mobilities that often accompany them. The disruptions that debates about the transformation of Scotland's place in the UK or EU bring are frequently predated by comparable insecurities around geopolitical transformations such as the transition from living in socialist to free market regimes, accession to the EU, the global financial crash and the decade plus of austerity that has preceded it. Unfortunately, since Kay's investigation predated the EU referendum, her data cannot tell us the extent to which Brexit was experienced as a deeply traumatic phenomenon by the migrants in her study. However, the insights gleamed from her research might lead one to speculate that some ECE migrants, despite their often disadvantageous socio-economic standing, are more resilient (or even apathetic) to geopolitical shocks such as Brexit than is assumed (Nowicka, 2020). Scholarly concerns with how Brexit will shape the migration experiences and settlement preferences of migrants may need to be more nuanced in order to account for how previous exposure to geopolitical upheaval and more immediate day-to-day economic concerns might trump a change in the constitutional status of their state of residence in terms of longer term settlement plans. 
Following up on the theme of predating insecurities being aggravated by the Brexit process, Colin Clark's piece focuses on arguably one of the most marginalised and vulnerable groups in the contentions that surround migration, the Roma community in Govanhill, Glasgow. As with Kay's paper, here we learn about how Brexit needs to be thought of as a drawn-out process which represents a continuation and potential exacerbation of existing inequalities and prejudices. Clark reports that the Roma have been at the sharp end of a post-Brexit hardening of already ingrained and damaging attitudes and policy practices. This includes practical barriers to gaining official Settled Status and increased Home Office hostilities in the years following the referendum. The ramifications are that the Roma and many of the other nearly 4 million EU nationals currently resident in the UK are left playing a tortuous 'waiting game' to find out how their status will ultimately be determined by a shock referendum result four years previously. As we have already learned from some of the other articles in this special issue, we must be careful to contextualise Brexit within the many other challenges that migrants face. Whilst undoubtably a major source of disruption, concerns about belonging sit alongside more prosaic everyday preoccupations: earning a living, going to school and looking after the family. Finally, Clark makes the interesting point that independence is essential for the protection of freedom of movement in Scotland. Whilst this is of course technically correct, returning to some of the points raised about Scottish distinctiveness, it may be worth considering how public perceptions sit with this aspiration. Migration not being a particularly politically salient issue in Scotland probably works in favour of proponents of it. However, given public opinion on the matter, it may be inadvisable to base a future political campaign on the message that one of the main reasons why Scotland needs independence is freedom of movement.

The extent of hostility to immigrants is a point Daniela Sime considers in her paper on the processes of identity negotiation that young ECE migrants have gone through in the context of Brexit. Rich in empirical evidence and original in that employs an innovative methodological approach to shed light on how young people in particular in the post-referendum period see their nationalities, Sime's analysis highlights some of the tensions and nuances of belonging in post-Brexit Scotland. As noted by others in this special issue and elsewhere, commendable efforts to promote an inclusive form of national identity are not necessarily matched by the realities of everyday experience for ethnic minorities in Scotland. Most of Sime's participants reported being victims of prejudice-based bullying behaviour and many provided harrowing accounts of the overt hostility they had faced. That said, the vast majority of survey respondents 
felt that they 'belonged' in the UK, nearly half described themselves as having an at least Scottish and/or British identity and there did not appear to an either-or dichotomy between feeling European and belonging in Britain. A key lesson to emerge from this research is that the narrative of Scottish exceptionalism is inevitably more complex than many of us would like. Immigration was clearly weaponised to considerable effect by the Leave campaign in the Brexit referendum. How this issue will play out in ongoing debates about Scotland's constitutional future is less straightforward. Scotland has distinct demographic needs and has a strong case for greater autonomy over immigration policy. However, as this special issue has demonstrated, we should not underestimate the level of hostility to immigration and immigrants that exists in Scotland. How this translates into the politics of Scotland's constitutional future over the longer term is an intriguing question which will no doubt occupy the minds of scholars in the turbulent years to come.

\section{Practical questions of citizenship(s) and "settled" status following Brexit}

The papers discussed in the previous section generated laudable insights into how ECE migrants perceive their sense of belonging in Scotland in the context of shifts in its relationship in the UK and the EU. A third key theme was how these perceptions translate into the actual practices of migrants with regards to the acquisition of formal citizenship.

In their paper, Kate Botterill and colleagues illustrate the varying degrees of ambivalence, compliance and reluctance of Polish nationals living in Scotland towards the EU Settlement Scheme through three vignettes. The experiences of Marek, Monika and Weronika echo the points made in the other papers about Brexit and its implications serving to compound existing intersecting vulnerabilities. Seemingly straightforward bureaucratic formalities such as applying for and getting Settled Status can actually evoke emotional trauma in addition to more practical challenges such as the provision of sufficient evidence and access to the relevant technology and the digital proficiency to use it. As a consequence of this scheme and other Brexit related uncertainties, the experiences reported by participants serve to emphasise the extended period of bureaucratic limbo that significant numbers of EU nationals find themselves in through no fault of their own. Brexit could thus undermine the progress that has been made on some fronts towards the integration of New Scots in Scotland, which the paper suggests a number of useful policy remedies for. The authors should also be applauded for their efforts to 
situate the documented precarities around citizenship in post-Brexit Scotland within the context of the catastrophic 2020 covid-19 pandemic. As they note, it may well result in increased risk of non-applications, delays to applications being made and in the processing of them. An area that is ripe for future research is how this crisis will compound the existing inequalities that this special issue has demonstrated have already been inflated by the drawn-out ongoing trauma of Brexit. The coming years will likely simultaneously see: covid-19 related economic turbulence, the UK exit the transition period and enter a new immigration policy regime and an intensification of debates over Scotland's constitutional future. If many migrants are already in vulnerable positions in terms of material and psychological aspects of citizenship and belonging then these events will likely worsen them.

The paper from Emilia Piętka-Nykaza and Derek McGhee follows up on the theme of the initial responses, intentions and experiences of Polish migrants to recent geopolitical change, but in the wider context of both the Scottish independence and Brexit referendums. The evidence presented here neatly corresponds with the emphasis by Botterill and others on the bureaucratic liminal 'grey area' whereby European migrants are neither completely included nor excluded in terms of their voting rights and other important aspects of citizenship and have faced an extended period of 'not knowing' how these issues will be resolved. ECE migrants find themselves in a peculiar situation in this respect. In theory, as European citizens, they are in a privileged position compared to non-EU migrants in the UK (Raji, 2017). However intraEuropean inequalities in terms of core-periphery divisions and social hierarchies between West and East (and North and South) mean that Brexit is a highly asymmetrical process in relation to EU citizens in the UK (Antonucci and Varriale, 2020). Rather than the conventional state centric understandings of citizenship rights, this paper aptly focuses on the practices and processes of citizenship formation during times of political uncertainty. The analysis is quite innovative in that it engages with migrants in the context of the Scottish independence referendum and then subsequently reengages with many of them following the Brexit vote. The authors might have made greater utility of this rare longitudinal perspective to shed light on how feelings of belonging and citizenship practices actually changed over time in the context of these transformations. Nonetheless the findings generate very interesting insights into how the two referendums have shaped issues of political participation, formal citizenship status and feelings of belonging. Of particular note is the increased attachment felt towards Scotland as a consequence of being given the right to vote in the independence referendum and the 
corresponding negativities that the lack of a say in the Brexit vote and its outcome generated. As with many of the other articles in this special issue, this analysis serves as a timely reminder that citizenship involves a range of complex subjective and objective dimensions that go beyond formal citizenship status. The nuances of how migrants interpret and act on these various aspects of citizenship in the context of socio-political and geographical transformations has considerable repercussions for how identities and belonging are perceived, conceptualised and responded to in theoretical and practical terms and has been a key contribution of this special issue. Another important reminder for researchers and others is that migrants, however vulnerable, have agency and exercise it strategic ways. Piętka-Nykaza and McGhee's Polish respondents, and presumably many others, have responded to the sadness, despair, confusion, anger and disappointment induced by Brexit by taking proactive steps to protect their rights. Going forward, scholars could aim to quantitatively monitor the extent of engagement in these tactics (e.g. applications for Settled Status and naturalisation) and draw on qualitative perspectives to aid explanation of whether and how resentment towards Brexit is translating into resilience in the face of it.

\section{Final thoughts}

It has been a privilege to offer my reflections on these valuable and timely contributions to the emerging literature on Brexit and questions of citizenship, identity and belonging in the Scottish context. These issues are far from resolved and this special issue will now doubt inform scholarship on them in important ways. With this in mind, I conclude with three final thoughts on the many significant themes that have been covered.

1. The notion of Scottish exceptionalism has gained increasing currency in political and media narratives, especially post-Brexit, and this rightly was an issue considered by many of the papers in this issue. An obvious avenue of enquiry here relates to whether this is indeed merited, and the evidence presented here and elsewhere is mixed in this respect. However, another pertinent question relates to the discursive power of this narrative. Regardless of its veracity, if Scots are led to believe that they are relatively welcoming of newcomers, might this not feed through into more positive perceptions and practices at the individual level. Likewise, if potential migrants believe Scotland to be welcoming, presumably it increases their likelihood of moving there (and boosting Scotland in demographic and economic terms in the process)? Greater research on how 
the narrative of Scottish exceptionalism is perceived, and its more tangible effects in terms of (in)hostility towards migrants and the decision making of migrants themselves would thus be welcome.

2. The papers in this special issue have underlined the fact that, for many migrants, Brexit is yet another addition to the list of disruptions to their life projects and pressures on their everyday lives. Research on its effects should see it in this context and should be wary of fetichising it as a sudden and unforeseen event which shattered the otherwise utopian existence of ECE migrants in Scotland. Brexit has clearly had significant negative impacts on issues of identity, citizenship and belonging as have been documented here. However, many migrants have also shown remarkable resilience in the face of this and other geopolitical challenges. Going forward, research could fruitfully aim to shed light on the heterogeneity of perception, experience and response to Brexit amongst ECE migrants. This could include sensitivity to its relationship with the less remarkable but potentially at least equally burdensome challenges that many of these migrants face in their day-to-day lives.

3. Finally, this special issue has served as a reminder that Brexit is not an event that is 'done', nor will it be when Britain exits its current 'transitional' phase with the EU (in 7 months at the time of writing). Rather it is a protracted process that has been a source of anxiety and anguish for many of Scotland's residents, not least those from abroad who have elected to make it their home. Looking forward, there will be more Brexit related tension to come. Simultaneously, debates over Scotland's place in the United Kingdom will intensify. The current time must therefore rank as one of the most constitutionally tempestuous periods in Scotland's recent history, and migrants frequently find themselves at the sharp end of these turbulences. The uncertainty they face will be greatly exacerbated by the other great unprecedented crisis of our time: covid-19. Society will be changed dramatically by this pandemic and it is paramount that existing inequalities are not widened further as a consequence of it. The social science community will continue to be a vital component of this endeavour.

\section{References}

Antonucci, L. and Varriale, S. (2020). 'Unequal Europe, unequal Brexit: How intra-European inequalities shape the unfolding and framing of Brexit'. Current Sociology 68(1). pp 41-59. 
Bonino, S. (2019). 'Discrimination against Muslims in Scotland'. In I. Zempi and I. Awan (eds) The Routledge International Handbook of Islamophobia. Taylor and Francis. London. pp 161-174.

Botterill, K. (2018). 'Rethinking "community" relationally: Polish communities in Scotland before and after Brexit'. Transactions of the Institute of British Geographers 43. pp 540- 554.

Botterill, K. McCollum, D. and Tyrrell, N. (2018). 'Negotiating Brexit: Migrant spatialities and identities in a changing Europe'. Population, Space and Place 25. pp1-4.

Curtice, J. and Montagu, I. (2018). 'Do Scotland and England \& Wales Have Different Views About Immigration?'. NatCen. Available at: http://natcen.ac.uk/our-research/research/doscotland-and-england-wales-have-different-views-about-immigration/

Accessed 30 ${ }^{\text {th }}$ April 2020.

Davidson, N. (2018). No problem here: understanding racism in Scotland. Luath Press. Edinburgh.

Duda-Mikulin, E. (2019). EU Migrant Workers, Brexit and Precarity. Policy Press. Bristol. Gawlewicz, A. and Sotkasiira, T. (2020). 'Revisiting geographies of temporalities: The significance of time in migrant responses to Brexit'. Population, Space and Place 26(1). pp 19.

Hepburn, E. (2020). 'Social and Equality Aspects of Brexit'. Available at: https://www.gov.scot/publications/social-equality-impacts-brexit/

Accessed 30 ${ }^{\text {th }}$ April 2020.

Leith, M. and Sim, D. (2019). 'The Scots in England - a different kind of diaspora?'. National Identities 21(2). pp 119-134.

Leith, M. and Soule, D. (2011). Political Discourse and National Identity in Scotland. Edinburgh. Edinburgh University Press.

Loopstra, R. (2020). 'Vulnerability to food insecurity since the COVID-19 lockdown'. The Food Foundation. Available at:

file://C:/Users/dm82/Desktop/Publications/Scottish\%20Affairs/Other\%20papers/Loopstra\% 202020.pdf

Accessed $8^{\text {th }}$ May 2020. 
Lulle, A. Moroşanu, L. and King, R. (2018). 'And then came Brexit: Experiences and future plans of young EU migrants in the London region'. Population, Space and Place 24(1).

McCollum, D. Nowok, B. and Tindal, S. (2014). 'Public attitudes towards migration in Scotland: Exceptionality and possible policy implications'. Scottish Affairs 23(1). pp 79-102.

Meer, N. (2015). 'Looking up in Scotland? Multinationalism, multiculturalism and political elites'. Ethnic and Racial Studies 38(9). pp 1477-1496.

Mostafa, I. (2018). Migration of Farm Workers to Rural Scotland. AuthorHouse. Bloomington, IN, USA.

Mulvey, G. and Burnett, A. (2019). 'Migration and identity in post-referendum Scotland'. National Identities 21(2). pp 135-149.

Nowicka, M. (2020). 'Uni-Culti'Myths and Liberal Dreams: Brexit and Austerity from the Perspective of Migrants'. In M. Guderjan, H. Mackay and G. Stedman (eds) Contested Britain: Brexit, Austerity and Agency. Bristol University Press. Bristol. pp 145-160.

Raji, S, (2017). 'Thoughts from an anti-model migrant wading through Brexit'. Capital \& Class 41(2). pp 344-350.

Scottish Government. (2020). 'Migration: helping Scotland prosper'. Available at: https://www.gov.scot/publications/migration-helping-scotland-prosper/pages/13/

Accessed 30 ${ }^{\text {th }}$ April 2020.

Sigona, N. and Godin, M. (2019). 'EU families in Scotland after the Brexit Referendum', Eurochildren Brief Series, no. 8. Available at: https://eurochildrenblog.files.wordpress.com/2019/09/eurochildren-brief-8-sigona-godinscotland.pdf

Accessed 30 ${ }^{\text {th }}$ April 2020. 